\title{
Improving the operational efficiency of tractors by ensuring their ability to perform work
}

\author{
Sergej Yahin ${ }^{1}$, Fanil Gabdrafikov ${ }^{2}$, Farit Khaliullin ${ }^{1}$, Rail Khusainov ${ }^{1}$, and Insaf Naficov ${ }^{1}$ \\ ${ }^{1}$ Kazan state agrarian University, 420015 Kazan, Russia \\ ${ }^{2}$ Bashkirian state agrarian university, $450001 \mathrm{Ufa}$, Russia
}

\begin{abstract}
Development of agriculture in conditions of market relations is accompanied by aggravation of the problem of efficiency of use of technics. In this connection, the task of scientists is to increase the actual volume of work performed by tractor units, reducing the cost per unit of production. The high cost of tractors, the lack of personnel, the reduction of technical equipment of farms and the increase in the volume of products produced in the agro-industrial complex, natural and climatic conditions impose special requirements on technical service to maintain tractors in working conditions. The working state of tractors is the state at which values of parameters, which characterize ability to execute the given functions, correspond to normative-reference and design documents. During the operation of tractors in agriculture under the influence of various factors, wear of their parts and knots. The indicator determining the value of wear is the residual resource of aggregates and knots of technics. In the article the questions of influence of residual resources of basic aggregates and systems of tractor on frequency of failures of various groups of complexity are considered. Experimental research on determination of dependencies of residual resources of tractor units and frequency of failures of different groups of complexity, on the basis of which the rules of replacement of the unit whose resource are exhausted, is carried out, i.e. is replaced with a full of the resource (new) or on the aggregate after overhaul.
\end{abstract}

\section{Introduction}

Operational reliability of the tractor, wear and ageing of aggregates, knots define its basic operational and economic parameters in performance of operations of agrarian production and depend on conditions of work [1].

The current system of repair and service works can not ensure the reliability of operations in crop production because of the lack of methods to optimize the timing and volume of repair and service effects of the machinetractor park with considering residual resources of aggregates, knots of technics and conditions of functioning of tractors as a whole. Due to the low operational reliability of tractors, there is a significant over-expenditure of labour and material resources.

Due to the low operational reliability of tractors, there is a significant over-expenditure of labor and material resources. The situation is holding back the decisions of the most important state tasks on efficient operation of machinery in agriculture.

At present, the system of maintenance and repair is developed on the basis of the planned and preventive principles of carrying out of repair and service influences. The base of system optimization is information about durability of structural elements of machines and results of diagnostics of aggregates and systems of technics. As a result of using the received information there is an opportunity to study regularities on formation of expenses on maintenance of tractors efficiency, and to realize effective processes of their maintenance and repair $[1,2]$.

Substantiation of periods of carrying out repair works of tractors is executed proceeding from volume of executed works, using regularities of change of repair costs that does not allow one to predict periodicity of repair and expenses for its carrying out under various conditions of agricultural production taking into account residual resources of aggregates and systems of technics. Therefore, at present there are no methods of improvement of the system of maintenance and repair of tractors by application of management decisions.

\section{Conditions, materials and methods of research}

For the purpose of optimization, the choice of the tractor for performance of planned technological operations and works on maintenance and repair taking into account their technical condition, organization on management of reliability indicators of technics, it is expedient to present it in the form of a calendar plan. This will provide an opportunity to predict the dynamics of production processes, as well as to estimate the planned volumes of work in terms of their feasibility. During the

\footnotetext{
* Corresponding author: drgali@mail.ru
} 
optimization of managerial actions, specificity of the use of machinery in agriculture, i.e. the need for a large number of techniques that have different values of residual resources, the influence of factors that do not depend on the person, etc., create certain obstacles.

Since, at present, the main source of improvement in the management of the production process is domestic reserves, i.e. without attracting labor and material resources, the value of the schedule is particularly increasing.

Analyzing the calendar plans, you can get data on the availability of resources for money, fuel and lubricants, spare parts, etc., which are necessary to carry out the planned work.

However, the systems considered in development have no single-step solution. In this connection, to solve the problem in dynamics, i.e. transformation into a task with a multi-step optimization, the decision should be taken for a certain number of steps forward. In contrast to the solution of single-step tasks, where optimization was important, in a multi-step solution, not only determined the program of optimization process development, but also considered the possibility of its practical implementation, that is organization of process management.

The solution of a multi-step task can be considered as static when attracting methods of mathematical programming. It should be taken into account that the parameters obtained in solving the problems of linear and nonlinear programming may be too large, that the possibility of their solution, even with the help of modern computer technology can be questioned. In this connection, a more effective solution of this type of problem is the variation approach, called "Discrete principle of maximum" [3].

The condition of the tractor, its operability, is determined by the residual resources of its aggregates and systems. Depending on the change in the residual resource of the tractor units and systems, the reliability indicators will change. It is therefore necessary to conduct pilot studies to identify these dependencies.

The frequency of failure of the tractor units was determined by the following formula [4]:

$$
T_{o}(H)=\frac{\Delta H}{\tilde{m}(\Delta H)}, \mathrm{H} \in \Delta \mathrm{H},
$$

$\tilde{\mathrm{m}}(\Delta \mathrm{H})$ - mathematical expectation of the number of tractor failures in the interval $\Delta \mathrm{H}, \mathrm{h}$.

The collection of information in the operating conditions for the evaluation of the reliability of tractors was carried out in accordance with [4]. Frequency of observations is at least 2 times a month. For each observed tractor the Journal of observations of the recommended form was built.

The information on refusals was presented in the observation sheets: the date of failure, the tractor's operating hours from the beginning of observations to the moment of failure, the name of the failed unit, a brief characteristic of failure. Recommendations [4] were used in the failure characterization.

The regularities of changes in the number of failures of the tractor system aggregates depending on their residual resources were determined using the method of determining the optimal type of dependence according to the criterion of minimum residual dispersion, developed in $[5,6]$.

\section{Results of the study}

Replacement of the unit is carried out before the occurrence of breakdowns on the size of the wear of aggregates and systems, which is determined by its residual resource. It is possible to replace several aggregates at the same time.

Replacement of other units of the tractor at the same time during the repair of one unit, involves performing some operations once, for example, transportation, washing, disassembly and assembly, painting, burnishing, etc. This reduces the downtime of the machine, the likely failure of aggregates that have a low residual resource.

However, replacement of other tractor units simultaneously during the repair of one knot can lead to underuse of the pledged technical resource of aggregates. In this regard, the option of simultaneous replacement is advisable to justify the economic criterion, by conducting a comparative analysis of the costs of maintaining the efficiency of the equipment for other options.

By the first variant the replacement of other units of the tractor simultaneously in repair of one knot which has exhausted the resource is foreseen. In this case, the cost of $S_{l}$, for replacement is defined as the sum of costs for the purchase of the unit and costs associated with the elimination of possible failures in the further use of the tractor, which are determined by the residual resources of their aggregates and systems.

In the second variant, when other units of the tractor are not replaced simultaneously during the repair of one knot, the cost of $S_{2}$ is calculated as a result of summing up the costs of eliminating the consequences of failures. This depends on the size of the residual resource and costs associated with the replacement of aggregates after the expiry of the resource.

When the $S_{1} \leq S_{2}$ condition is executed, the work node must be replaced at the same time as the failed. If the condition is not satisfied, the replacement of the unit simultaneously with the failed aggregate economic is not advisable.

In case of economic inexpediency of carrying out of the current repair and at inability of the tractor to carry out work, it is sent for capital repair.

The time of finding the machine in technical service (TS) is determined by normative documents. When using tractors in agricultural work we should take into account only the time of the tractor at TS-3, because TS-1, TS-2 are held outside the time shift.

The time spent on carrying out of the current repair of tractors is defined as the sum of time connected with elimination of consequences of failures and time by the preventive replacement of aggregates. The duration of elimination of the consequences of failure is determined depending on the difficulty groups $[7,8]$. The time to 
replace the unit is determined by the technology cards [9].

Sudden failure of any unit, as a rule, is connected with failure of one of its elements, leads to infringement of its efficiency. The need to assign a major overhaul of the unit or system is justified by the failure condition of the element determining their technical resources. The unit should be dismantled and replaced with a workable one.

However, two variants of replacement of the aggregate are possible, i.e. the aggregate, the resource of which is exhausted, is replaced by the aggregate with full reserve of a resource (new) or on the aggregate after overhaul. In this case, the frequency of failures of other tractor units should be taken into account.

The tractor motor should be considered separately, because the labor and cost of eliminating the consequences of failures in comparison with other aggregates of the tractor is of the greatest importance.

Replacement of the engine node is based on the resource of the exchange node taking into account the engine failure frequency:

$$
t_{s j}^{0} \geq T_{\text {re }}
$$

$t_{s j}^{0}$-- residual resource of the exchange unit, h.; $T_{r e}-$ frequency of failure of the tractor engine, $h$.

The condition of replacement of aggregates of other systems of the tractor is the value of the residual resource of the exchange unit determined by its work in periods before or between overhauls, i.e.:

$$
t_{s j}^{0} \geq T_{r r} .
$$

If the equipment is new or after overhaul, it is necessary to consider the normative volume of work for the tractor. When carrying out the next TS-3, we specify the recommended volume of work for the tractor before the first overhaul and in the periods after the first and second overhaul.

To estimate the resource of the tractor node after overhaul in practice, the average value of the residual resource is taken into account, since the change of resource of the main units of tractor has normal distribution law and average value of its residual resource is the most probable. When carrying out the next TS-3 residual resources of residual aggregates and systems of technics are specified.

The average resource of new nodes is greater than the average resource of nodes after overhaul [10]. Proceeding from the condition (1) it is possible to deduce that the residual resource of the auxiliary node of the engine, which should be replaced, should not limit a resource of all engine. And the condition (2) indicates that the aggregate which has been replaced should have the residual resource is more than the resource of the tractor after its first and second overhauls. At the same time, it should be assumed that the choice of replacement did not limit the resources of the main units of the tractor, as well as the cost of replacement was minimal, because the new unit has not only a maximum residual resource, but also a greater cost than that of assembly after overhaul.
Based on the above judgments, there is a need to introduce a node selection rule to replace a failed or node with a smaller resource. Rules established that:

- if the frequency of engine failure is less than the average residual resource of the unit after overhaul, you should select the node after overhaul;

- if the frequency of engine failure is greater than the average residual resource of the unit after overhaul, you should choose a new unit.

The rules of the exchange unit selection for other parts of the tractor can be formulated in the same way, but as a main part of it should be selected as the resource-intensive system, which includes the exchange unit. In other words, the recovery of the $j$-th unit can be determined in conditions of (1), (2) as follows:

- for engine aggregates:

$$
t_{s j}^{0}=\min \left\{\overline{t_{s j n}} \mid \overline{t_{s j r}} \geq T_{e}\right\}
$$

- for other tractor aggregates:

$$
t_{s j}^{0}=\min \left\{\overline{t_{s j n}} \mid \overline{t_{s j r}} \geq T_{m}\right\},
$$

$\overline{\mathrm{t}_{\mathrm{sjn}}}, \overline{\mathrm{t}_{\mathrm{sjr}}}-$ residual resource of the new and overhauled $\mathrm{j}$-th aggregates.

As a result of experimental researches numerical values on sudden failures of various groups of complexity of systems of tractors which were under supervision have been received. Residual resources of the tractor system aggregates were recorded at the beginning of the observations, besides during the experimental studies the appearance of failures corresponding to each observation was recorded. The obtained results are processed using the computer according to the developed program.

The patterns in the form of formulas, as well as the correlation coefficients and their errors, which can be judged on the tight relationship between variable parameters and response functions, are presented in table 1.

The adequacy of the obtained dependencies was tested by comparing the failure of tractors in the farms that did not participate in the experimental studies with the data obtained from the formulas in table 1. With a probability of 0.95 , the value of the trust interval for the failure does not exceed $6 \%$ of the value obtained from these dependencies.

The obtained results showed that with the change of the residual resource of constituent units the operating hours for failure of tractor systems in the groups of complexity are changed as follows (table 2).

From table 2 it is visible that in the investigated zone, limits of change of frequency of failures for different systems of tractor are different. Obviously, the greater the difference between the maximum and minimum values of the frequency of failure of the tractor systems, the more its operational reliability depends on external factors, such as the quality of maintenance, quality Fuellubricants, quality of maintenance, natural-climatic, etc. In this connection, the development of measures to ensure the efficiency of the tractor on these systems should be considered. 
Table 1. Dependences of influence of residual resource of tractor systems on frequency of failures of different groups of complexity

\begin{tabular}{|c|c|c|c|c|c|}
\hline № & Tractor systems & $\begin{array}{l}\text { Difficulty } \\
\text { group } \\
\text { breakages } \\
\end{array}$ & $\begin{array}{l}\text { The equation of the volume of work performed to } \\
\text { the failure and residual resource, } h\end{array}$ & $\begin{array}{l}\text { Correlation } \\
\text { coefficient }\end{array}$ & $\begin{array}{c}\text { Error of } \\
\text { correlation } \\
\text { coefficient [11] }\end{array}$ \\
\hline \multirow[t]{3}{*}{1} & \multirow{3}{*}{ Engine } & $\mathrm{I}$ & $T_{o \mathrm{e}}^{I}=27 \cdot T_{o c m}^{0.51}-610$ & 0.68 & 0.18 \\
\hline & & II & $T_{\mathrm{o} e}^{I I}=0.895 \cdot T_{r}-170.23-7.8 \cdot 10^{-5} \cdot T_{r}$ & 0.62 & 0.17 \\
\hline & & III & $T_{o \mathrm{e}}^{I I I}=5319.9 \cdot \lg T_{r}-15443.8$ & 0.59 & 0.15 \\
\hline \multirow[t]{3}{*}{2} & \multirow{3}{*}{ Transmission } & I & $T_{o e}^{I}=29.12 \cdot T_{r}^{1.543}-902.58$ & 0.69 & 0.2 \\
\hline & & II & $T_{o t}^{I I}=778.12 \cdot T_{t}^{0.249}-3948.51$ & 0.75 & 0.21 \\
\hline & & III & $T_{o t}^{I I I}=626.65 \cdot T_{r}^{-2.51}-3735.79$ & 0.62 & 0.16 \\
\hline \multirow[t]{2}{*}{3} & \multirow{2}{*}{$\begin{array}{l}\text { Electrical } \\
\text { equipment }\end{array}$} & I & $T_{o e l}^{I}=T_{r} /\left(2.17-3.36 \cdot 10^{-4} \cdot T_{r}\right)$ & 0.81 & 0.22 \\
\hline & & II & $T_{o \text { el }}^{I I}=1033 \cdot T_{r}^{0.269}-5997.19$ & 0.52 & 0.17 \\
\hline \multirow[t]{2}{*}{4} & \multirow[t]{2}{*}{ Hydrosystem } & I & $T_{o h s}^{I}=7477.79+16797.19 \cdot T_{r}^{0.119}$ & 0.62 & 0.18 \\
\hline & & II & $T_{o h s}^{I I}=4735.9 \cdot \lg T_{r}-13395.57$ & 0.59 & 0.12 \\
\hline
\end{tabular}

Table 2. Limits of changes of frequency of failures of tractor systems by groups of complexity

\begin{tabular}{|c|c|c|}
\hline \multirow{2}{*}{$\begin{array}{c}\text { Complexity } \\
\text { group }\end{array}$} & $\begin{array}{c}\text { Limits of change of frequency of failures } \\
\text { of tractor systems during observation, } \mathrm{h}\end{array}$ \\
\cline { 2 - 3 } & minimum value & maximum value \\
\hline \multicolumn{3}{|c|}{ Engine } \\
\hline I & 434.7 & 1562 \\
\hline II & 781.2 & 2500 \\
\hline III & 1000 & 4761.9 \\
\hline \multicolumn{3}{|c|}{ Transmission } \\
\hline I & 400 & 2500 \\
\hline II & 526 & 2631 \\
\hline III & 714 & 3125 \\
\hline \multicolumn{3}{|c|}{ Electrical equipment } \\
\hline I & 456 & 3333 \\
\hline II & 680 & 4000 \\
\hline \multicolumn{3}{|c|}{ Hydraulics } \\
\hline I & 730 & 3012 \\
\hline II & 917 & 3448 \\
\hline
\end{tabular}

In accordance with the conditions $(1,2)$, which define the rules of exchange of the tractor aggregates during the repair of their systems, the values of the frequency of failures, given in table 2, provide the possibility to make the following decisions:

- if the resource of the capital-repaired exchange unit is higher than the minimum frequency of failure of the III group of engine or tractor transmission, it is advisable to replace it with the repaired unit;

- if the frequency of failure of the III group of the engine or transmission of the tractor has a maximum value and higher, the Exchange unit must be new. The rules for the electrical equipment and hydraulic system of the tractor are the same; only failures II group difficulty should be considered.

\section{Conclusion}

- the arguments on the need to develop measures to ensure the efficiency of tractors in agricultural production are given;
- the results of experimental research in the form of dependences of change of frequency of failures of the tractor of various groups of complexity in performance of basic kinds of agricultural works depending on residual resources of systems are presented. Checking the adequacy of these dependencies allows us to conclude that with a probability of 0.95 the value of the confidence interval for the frequency of system failures, for tractors that did not take into account the experiment does not exceed $6 \%$ of the value obtained by these dependencies;

- based on the dependencies of changing the frequency of failure of the tractor for its main systems, depending on their residual resources, we revealed the maximum and minimum values of the frequency of failures;

- sing the presented formulas, the maximum and minimum values of the frequency of failures we formulated rules of exchange of the unit during the repair of basic tractor systems. The application of these rules to ensure the fullest use of the resource aggregates and systems of the tractor helps prevent failures of various groups of complexity. This, in the final analysis, ensures the efficiency of tractors in agricultural production.

\section{References}

1. I.G. Galiev, K.A. Khafizov, N.R. Adigamov, R.K. Khusainov, 17th ISC Engineer. for rural developm. Proc., 17, 373 (2018)

2. I.G. Galiev, A.A. Mukhametshin, I.R. Iskhakov, A.R. Shamsutdinov, Herald of Kazan state agricult. Univer., 5(3(17)) (2010)

3. K.A. Novikov, Abstract of dissertation (2017)

4. OST 70.2.8-82. Tests of agricultural machinery (1982)

5. F.H. Khaliullin, I.G. Galiev, Herald of Kazan state agricult. Univer., 6(2(20)) (2011) 
6. R.N. Khusainov, K.A. Khafizov, A.A. Nurmiev, I.G. Galiev, 17th ISC engineer. for rural develop. proc., 168-175 (2018)

7. I.G. Galiev, Herald of Kazan state agricult. Univer., 9(2(32)) (2014)

8. A.M. Pavlov, V.I. Tsyrobov, Packaging, transportation, storage of machinery and equipment (1984)
9. V.P. Boykov, Diagnostics of technical condition of machines (2012)

10. GOST 27.307-86. Reliability in technology (1986)

11. O.P. Krastin, Methods of regression and correlation analysis (1970) 